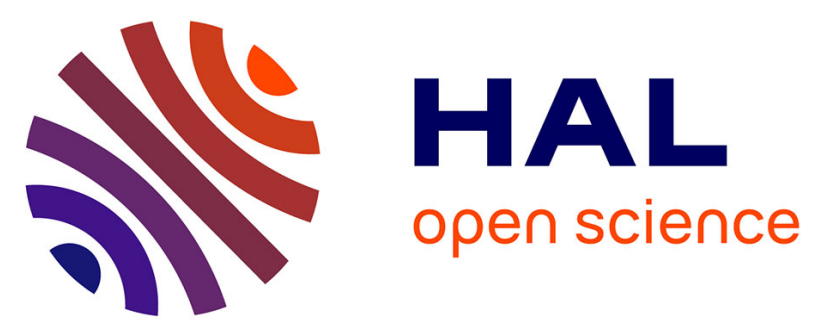

\title{
Impact of medication characteristics and adverse drug events on hospital admission after an emergency department visit: prospective cohort study
}

Laura Lohan, Gregory Marin, Marie Faucanie, Marion Laureau, Valérie Macioce, Damien Perier, Véronique Pinzani, Isabelle Giraud, Audrey Castet-Nicolas, Anne Jalabert, et al.

\section{To cite this version:}

Laura Lohan, Gregory Marin, Marie Faucanie, Marion Laureau, Valérie Macioce, et al.. Impact of medication characteristics and adverse drug events on hospital admission after an emergency department visit: prospective cohort study. International Journal of Clinical Practice, 2021, 75 (7), pp.e14224. 10.1111/ijcp.14224 . hal-03201650

\section{HAL Id: hal-03201650 \\ https://hal.science/hal-03201650}

Submitted on 16 Jun 2021

HAL is a multi-disciplinary open access archive for the deposit and dissemination of scientific research documents, whether they are published or not. The documents may come from teaching and research institutions in France or abroad, or from public or private research centers.
L'archive ouverte pluridisciplinaire HAL, est destinée au dépôt et à la diffusion de documents scientifiques de niveau recherche, publiés ou non, émanant des établissements d'enseignement et de recherche français ou étrangers, des laboratoires publics ou privés. 


\title{
Impact of medication characteristics and adverse drug events on hospital admission after an emergency department visit: Prospective cohort study
}

\author{
Laura Lohan $^{1,2}$ | Gregory Marin ${ }^{3}$ | Marie Faucanie ${ }^{3}$ | Marion Laureau ${ }^{1,4}$ | \\ Valérie Macioce $^{3}$ | Damien Perier ${ }^{4}$ | Veronique Pinzani ${ }^{5}$ | Isabelle Giraud ${ }^{6}$ | \\ Audrey Castet-Nicolas ${ }^{1}$ | Anne Jalabert ${ }^{1}$ | Maxime Villiet ${ }^{1}$ | Mustapha Sebbane $^{4}$ | \\ Cyril Breuker ${ }^{1,2}$
}

${ }^{1}$ Clinical Pharmacy Department, $\mathrm{CHU}$ Montpellier, Univ Montpellier, Montpellier, France

${ }^{2}$ PhyMedExp, Univ Montpellier, CNRS, INSERM, Montpellier, France

${ }^{3}$ Clinical Research and Epidemiology Unit, CHU Montpellier, Univ Montpellier, Montpellier, France

${ }^{4}$ Emergency Medicine Department, $\mathrm{CHU}$ Montpellier, Univ Montpellier, Montpellier, France

${ }^{5}$ Medical Pharmacology and Toxicology Department, CHU Montpellier, Univ Montpellier, Montpellier, France

${ }^{6}$ Economic Evaluation Unit, Univ Montpellier, CHU Montpellier, Montpellier, France

Correspondence

Cyril Breuker, Clinical Pharmacy

Department, University Hospital, Montpellier, 371 avenue du doyen Gaston Giraud 34295 Montpellier, France.

Email: c-breuker@chu-montpellier.fr

\begin{abstract}
Objectives: Emergency department (ED) overcrowding is a problem for the delivery of adequate and timely emergency care. To improve patient flow and the admission process, the quick prediction of a patient's need for admission is crucial. We aimed to investigate the variables associated with hospitalisation after an ED visit, with a particular focus on the variables related to medication.

Methods: This prospective study was conducted from 2011 to 2018 in subacute medical ED of a French University Hospital. Specialised EDs (paediatric, gynaecologic, head and neck and psychiatric) and the outpatient unit of the ED were not included. Participation in this study was proposed to all adult patients who underwent a medication history interview with a pharmacist. Pharmacists conducted structured interviews for the completion of the medication history and the detection of adverse drug events (ADE). Relations between patient characteristics and hospitalisation were analysed using logistic regression.

Results: Among the 14511 included patients, 5972 (41.2\%) were hospitalised including 69 deaths. In total, 7458 patients (51.4\%) took more than 5 medications and 2846 patients (19.6\%) had an ADE detected during the ED visit. In hospitalised patients, bleeding (32.2\%) and metabolic disorders (16.8\%) were the most observed ADE symptoms. Variables associated with increased hospital admission included 2 demographic variables (age, male gender), 4 clinical variables (renal and hepatic failures, alcohol addiction, ED visit for respiratory reason) and 6 medication-related variables (medications $>5$, use of blood, systemic anti-infective, metabolism and antineoplastic/immunomodulating medications and ADE).

Conclusion: We identified variables associated with hospitalisation including drugrelated variables. These results point out the importance and the relevance of collecting medication data in a subacute medical ED (study registered on ClinicalTrials. gov, NCT03442010).
\end{abstract}




\section{What's known}

- Emergency department is a major source of urgent or unexpected hospitalisation.

- Emergency department overcrowding is a problem for the delivery of adequate and timely emergency care.

- Reliable medication data are not immediately obtainable and can be time consuming to collect in emergency department.

\section{What's new}

- More than $40 \%$ of patients admitted to subacute medical emergency department (ED) were hospitalised.

- Polymedication and occurrence of an adverse drug event were independently associated with increased hospitalisation.

- Medication-related data are worthwhile to consider in the context of ED visit.

\section{1 | INTRODUCTION}

The emergency department (ED) is a major source of urgent or unexpected hospitalisation. Besides the significant cost associated with these unscheduled hospitalisations, estimated at more than $£ 13$ billion per year in England, ${ }^{1,2}$ they can also expose patients to various hospitalisation-related adverse events (such as stress, nutritional issues, infections) resulting in a general vulnerability. ${ }^{3}$ Thus, the reduction in emergency hospitalisation has become a priority and a longterm ambition, notably for health systems such as the National Health Service (NHS) in England. ${ }^{1,2}$ One possible approach is the identification of patients at high risk of emergency hospitalisation in order to implement targeted prevention measures in primary care. ${ }^{4}$ Several risk prediction models or other tools have been developed for this purpose, highlighting the risk factors of emergency hospitalisation from ambulatory care. ${ }^{5,6}$ They use various data sources (self-reported data, administrative databases, population registries, clinical records, etc) which enable a large number of candidate variables to be analysed: demographic data, lifestyle variables, chronic diseases, prescribed medication, clinical data, laboratory test results, etc. ${ }^{5}$

In parallel with these ambulatory models, other emergency admission risk prediction models have been developed for emergency department use. ${ }^{7-11}$ In addition to the potential aforementioned applications, they intend to quickly predict a patient's need for admission, to provide logistical support to the ED team and to improve patient flow and admission processes. Indeed, ED overcrowding is a problem for the delivery of adequate and timely emergency care. ${ }^{12}$ It is also a factor of patient dissatisfaction, with prolonged waiting times and lower morale and productivity for physicians. ${ }^{13,14}$ The rapid determining of patients most at risk of hospitalisation could be a solution to partly reduce this multifactorial phenomenon in the ED. These ED models generally use routinely collected and readily available data which are demographic, administrative as well as a few clinical variables. Medication data are virtually not tested in ED models, yet they are sometimes predictor variables of admission in ambulatory care models. ${ }^{5}$ It is currently estimated that drug-related problems account for $5 \%-15 \%$ of hospitalisation. ${ }^{15}$ In a previous study, we highlighted that $15.7 \%$ of patients admitted to the ED had an ADE, with a higher proportion of hospitalisation and death during the ED visit compared to patients without an ADE. ${ }^{16}$ Reliable medication data are not immediately obtainable and can be time consuming to collect, which may explain their low utilisation in ED models. In the ED of our hospital, a pharmacist team is routinely deployed to help the ED team by collecting the patients' medication history and detecting Adverse Drug Events (ADEs). In this study, we aimed to investigate variables associated with hospitalisation after the ED visit, using standard data collected in the ED, with a particular focus on variables related to medication.

\section{2 | METHODS}

\section{1 | Design}

This study is an ancillary analysis of a previously published study. ${ }^{16}$ This prospective study was conducted from November 2011 to November 2018 in the subacute medical ED of our University Hospital, France (2600-bed tertiary care centre). Paediatric, gynaecologic, head and neck and psychiatric EDs are physically separated from the medical ED and were not included in this study. The outpatient unit of the adult medical ED which treats non-urgent cases (small traumatology and benign pathologies) was also not included in the study. Our study was approved by the Hospital Institutional Review Board and registered on ClinicalTrials.gov (NCT03442010). All participants or a member of their family gave verbal consent.

\section{2 | Study population}

Participation in this study was proposed to all adult patients (>18 years) who underwent a medication history interview with a member of the pharmacist team, briefly after triage. Non-inclusion criteria were refusal to participate, voluntary medication poisoning or acute psychological problems. All patients were prospectively and consecutively included without any prioritisation criteria such as age 
or polymedication from Monday to Friday from 8.00 to 18.00 , and were followed until ED discharge.

\section{3 | Interventions and measurements}

Interventions have been published previously. ${ }^{16}$ Briefly, the ED staff includes a pharmacist team (1 senior pharmacist, 1 resident and 4 pharmacy students). The pharmacist team carried out a medication history and ADE detection for each included patient. The medication history was conducted following the standard operating procedures recommended by the World Health Organisation, ${ }^{17}$ as previously described. ${ }^{18}$ It was defined as the most comprehensive list of all medications taken by the patient, including prescription drugs, selfmedication (over the counter medication and herbal medication) and as-needed treatments. We also collected the self-reported adherence. The medication history is based on a structured interview of the patient (and/or relatives if needed) and additional sources such as medication prescription, medical record, and contact with community pharmacy, general practitioner or nurse. The entire process (data collection, cross-checking of information and validation of the final medication history) usually required 20-30 minutes. It could be started before or after the medical consultation depending on the availability of the pharmaceutical team but was performed independently and blindly from the medical management. An ADE was defined as "any injury resulting from medical intervention related to a drug", according to the Institute of Medicine's definition. ${ }^{19}$ ADEs were attributed to a medication by the pharmacist and confirmed, in real time, by the treating senior ED physician. In the case of doubt about the diagnosis or category of an ADE during the study, the case was reviewed by an expert committee that included ED physicians, clinical pharmacists and pharmacovigilance physician. At the end of the study, ADE cases were verified by 2 expert clinical pharmacists and/or the expert committee if necessary (Figure S1). The ADE severity was assessed according to the Common Terminology Criteria for adverse events as spontaneous regression, regression after symptomatic treatment, hospitalisation with no life-threat, lifethreatening risk and death.

All pharmacist team members received specific training on medication history realisation, according to the High $5 \mathrm{~s}$ project standard operating procedures ${ }^{17}$ and on ADE detection and documentation. ${ }^{20,21}$

The pharmacist team collected socio-demographic data (age, gender), the FRENCH triage scale level, ${ }^{22}$ clinical data (cause of ED visit, comorbidities), medications (number, ATC level 1 and 2), detection and characteristics of the ADE. These data were prospectively collected and recorded from the medical record and/or structured patient interview. The primary outcome was hospitalisation after the subacute medical ED visit. As already seen elsewhere, ${ }^{7}$ deaths in the subacute medical ED were counted as hospitalisation, because it was considered that the health condition of such patients would have led to an admission had they survived.

\section{4 | Analysis}

The patients' characteristics were described with percentages for categorical variables and means \pm standard deviations (SD) for quantitative variables. To assess the representativeness of our study sample, main characteristics of included patients were compared with those of the entire population of patients admitted to the medical ED (including the outpatient ED unit, which was excluded from our population). Such data were obtained retrospectively from the hospital's information systems medicalisation program.

Among the study population, the characteristics of patients with hospitalisation and without hospitalisation were compared with the Student's $t$ or the Mann-Whitney $U$ test for continuous variables, and with the Chi square or Fisher exact test for categorical variables.

The variables considered as candidate hospitalisation predictors included all data collected by the pharmacist team. The impact of our variables of interest on the primary outcome was analysed using logistic regression. The variables with $p$-values lower than 0.15 in univariate models were considered for a multivariable model. After a stepwise selection of variables, only the variables with $P$-values lower than .05 in the multivariable model were considered to be significantly associated with hospitalisation or death in the ED, and were kept in the final multivariate model. Missing data were not replaced and the absence of collinearity between the variables of interest has been verified. In order to assess multicollinearity in our regression models, the correlation matrix of the final parameters was executed, and both the Variance Inflation Factors and the proportion of variation using condition indices of linear combination of the parameters were analysed.

Statistical analyses were performed with SAS 9.1 (SAS Institute, France), and the statistical bilateral significance threshold was set at $5 \%$.

\section{3 | RESULTS}

\subsection{Characteristics of the study population}

Among the 210587 patients who visited the medical ED during the study period, accounting for 338592 admissions, 14619 patients (6.9\%) admitted to the subacute medical ED and benefiting from a medication history by pharmacists were included in the study. For 108 of them, an outcome was not available. Therefore, the study population consisted of 14511 patients, of which 5903 (40.7\%) were hospitalised after the subacute medical ED visit and 69 (0.5\%) died in the subacute medical ED. Thus, the primary outcome concerned 5972 (41.2\%) patients (Figure 1). Our study population had a higher mean age ( $64.6 \pm 24.7$ vs $47.5 \pm 22.6$ years), triage category ( $\leq$ level 3 FRENCH triage scale, $70.0 \%$ vs $45.6 \%$ ) and hospitalisation or death rate $(41.2 \%$ vs $20.1 \%)$ than the population admitted to the adult medical ED (including subacute medical ED but also the outpatient ED unit) during the study period (Table S1). 


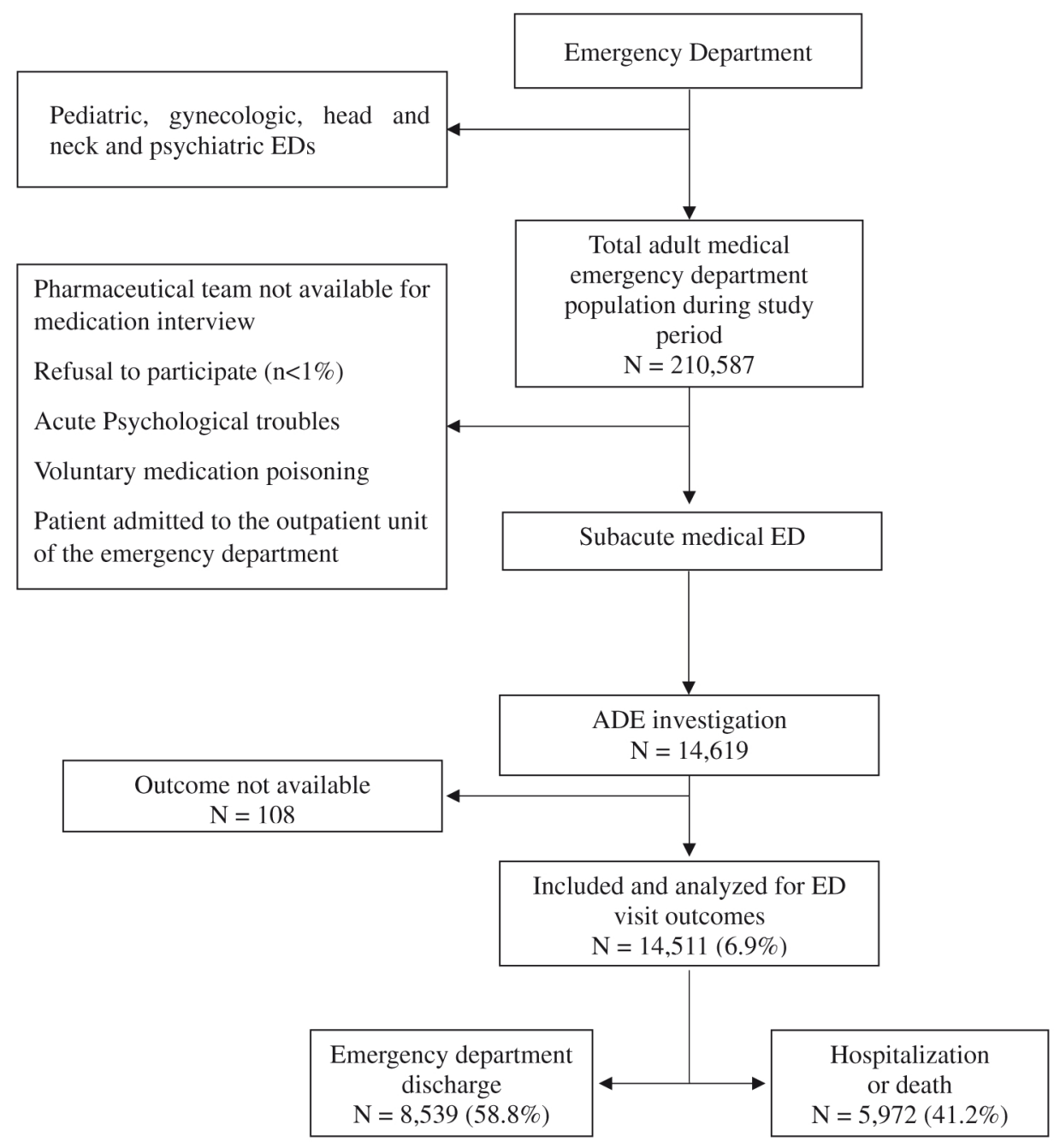

FIGURE 1 Flowchart of the study population. ADE, adverse drug event; ED, emergency department

The population baseline characteristics according to the ED visit outcome-discharge versus hospitalisation are described in Table 1. Among the hospitalised patients, age, proportion of men and proportion of patients living in an institution were higher. In both groups of patients, the main cause of the ED visit was gastroenteric, respiratory and cardiologic symptoms. Respiratory symptom was the cause of the ED visits that mostly led to hospitalisation, with $57.5 \%$ $(1036 / 1803)$ of patients hospitalised. A low triage category was more frequent among discharged patients $(12.4 \%$ vs $7.1 \%$ for level 5) while a high triage category was more common among hospitalised ones ( $4.6 \%$ vs $1.2 \%$ for level 1 ). In fact, the rate of hospitalisation increased with priority of care according to the triage category: $28.6 \%$ (420/1469) for level 5, 36.5\% (1035/2838) for level 4, 41.9\% (3241/7728) for level 3, 48.5\% (949/1958) for level 2 and $72.7 \%$ (274/377) for level 1 .

\subsection{Description of medication data}

Concerning medication treatment, 13600 patients (93.7\%) reported taking at least 1 medicine (chronic prescribed treatment or selfmedication). The majority (69.5\%) were on neurological medications and a significant proportion on drugs related to the alimentary tract and metabolism (63.2\%) and to the cardiovascular system (57.6\%). For all major class medications, the proportion of patients under treatment was higher in hospitalised patients than in discharged ones. Polypharmacy (number of medications greater than 5) was more frequent in hospitalised patients ( $63.5 \%$ vs $43.0 \%$ ), while the self-management of treatment was less common (62.6\% vs $76.5 \%)$.

In total, 88856 drugs were recorded: 45635 (51.4\%) among the 8539 patients further discharged, and 43221 (48.6\%) among the 5972 hospitalised patients. The distribution of these medications by ATC class (level 1 and 2 ) is presented in Table 2. Row percentages allow the likelihood of being in one or the other group to be highlighted given the class of drug prescribed. For the hospitalised group, the highest probability was observed with antineoplastic and immunomodulating agents for level 1 ATC class (56.1\%) and diuretics for level 2 (58.6\%).

\section{3 | Description of ADE symptoms}

As presented in Table 1, in 2849 patients (19.6\% of the total study population and $20.9 \%$ of patients taking at least one medicine), an ADE was detected during the ED visit. In total, $77.5 \%$ of them were 
TAB LE 1 Characteristics of the study population according to ED visit outcomes

\begin{tabular}{|c|c|c|c|c|}
\hline Characteristics & Missing data & TOTAL & Discharge & Hospitalisation \\
\hline $\mathrm{N}$ (\% of patients) & & 14511 & 8539 & 5972 \\
\hline Age (y) & 0 & $64.6 \pm 24.7$ & $59.5 \pm 23.0$ & $71.9 \pm 25.1$ \\
\hline Gender, male & 0 & $7003(48.3)$ & $3991(46.7)$ & 3012 (50.4) \\
\hline Body mass index $>30 \mathrm{~kg} / \mathrm{m}^{2}$ & 2500 & $1624(13.5)$ & $917(12.8)$ & 707 (14. 7) \\
\hline FRENCH triage scale & 141 & 14370 & 8451 & 5919 \\
\hline Level 1 & & $377(2.6)$ & $103(1.2)$ & $274(4.6)$ \\
\hline Level 2 & & $1958(13.6)$ & $1009(11.9)$ & $949(16.0)$ \\
\hline Level 3 & & $7728(53.8)$ & $4487(53.1)$ & $3241(54.8)$ \\
\hline Level 4 & & 2838 (19.8) & $1803(21.3)$ & 1035 (17.5) \\
\hline Level 5 & & $1469(10.2)$ & $1049(12.4)$ & $420(7.1)$ \\
\hline Type of ED unit & 19 & 14492 & 8526 & 5966 \\
\hline Emergency Critical Care Unit & & 464 (3.2) & $117(1.4)$ & $347(5.8)$ \\
\hline Observation Emergency Unit & & $12825(88.5)$ & $7901(92.7)$ & $4924(82.5)$ \\
\hline Short Stay Hospitalisation Unit & & $1203(8.3)$ & $508(5.9)$ & $695(11.6)$ \\
\hline Lifestyle & 34 & 14477 & 8516 & 5961 \\
\hline At home & & $12962(89.5)$ & $7717(90.6)$ & $5245(88.0)$ \\
\hline In institution & & $1515(10.5)$ & $799(9.4)$ & $716(12.0)$ \\
\hline Main cause of ED visit & 2 & 14509 & 8538 & 5971 \\
\hline Cardiovascular & & $1713(11.8)$ & $1176(13.8)$ & $537(9.0)$ \\
\hline Hepato-gastrointestinal & & $3080(21.2)$ & $2065(24.2)$ & $1015(17.0)$ \\
\hline Genitourinary & & $289(2.0)$ & $209(2.5)$ & $80(1.3)$ \\
\hline Respiratory & & $1803(12.4)$ & $767(9.0)$ & $1036(17.4)$ \\
\hline Neurologic & & $980(6.8)$ & $589(6.9)$ & $391(6.6)$ \\
\hline Self-medication & 0 & $4013(27.7)$ & $2715(31.8)$ & $1298(21.7)$ \\
\hline Daily medications $>5$ & 0 & $7458(51.4)$ & $3668(43.0)$ & $3790(63.5)$ \\
\hline Daily medications & 0 & $6.1 \pm 4.2$ & $5.4 \pm 4.1$ & $7.2 \pm 4.2$ \\
\hline Presence of ADEs & 0 & 2849 (19.6) & $1463(17.1)$ & $1386(23.2)$ \\
\hline Patient with at least 1 medication & 0 & $13600(93.7)$ & $7842(91.8)$ & $5758(96.4)$ \\
\hline Self-management of medications & 941 & $9585(70.6)$ & $5981(76.5)$ & $3604(62.6)$ \\
\hline \multicolumn{5}{|l|}{ Major class medications (ATC level 1) } \\
\hline Alimentary tract and metabolism & & $8593(63.2)$ & $4516(57.6)$ & $4077(70.8)$ \\
\hline Blood and blood-forming organs & & $6527(45.0)$ & $3189(37.4)$ & $3338(55.9)$ \\
\hline Cardiovascular system & & $8361(57.6)$ & $4214(49.3)$ & $4147(69.4)$ \\
\hline Nervous system & & $10,085(69.5)$ & $5720(67.0)$ & 4365 (73.1) \\
\hline Respiratory system & & $2,751(20.2)$ & $1544(19.7)$ & $1207(21.0)$ \\
\hline
\end{tabular}

Note: Data are the mean \pm SD, or $n(\%) ; F R E N C H$ triage scale level 1: Immediately life-threatening; level 2: Marked impairment of a vital organ, or imminently life-threatening, or functionally disabling traumatic lesion; level 3: Functional impairment, or organic lesions likely to deteriorate within $24 \mathrm{~h}$, or complex medical situation justifying the use of several hospital resources; level 4: Stable, non-complex functional impairment or organic lesions, but justifying the urgent use of at least one hospital resource; level 5: No functional impairment or organic lesion justifying the use of hospital resources;

Abbreviations: ADEs, adverse drug events; ATC, anatomical therapeutic classification; ED, emergency department.

involved in the ED visit. Patients with an ADE were hospitalised in $48.6 \%$ of the cases (1386/2849). Table 3 describes symptoms of ADE and shows differences between the 2 populations. In hospitalised patients, bleeding and metabolic disorders were the most observed ADE symptoms while, in the discharged group, it was neurologic disorders followed by bleeding. The largest differences in proportions between the discharged and hospitalised patients were observed for bleeding (20.1\% vs $32.2 \%$ ), haematology and coagulation test abnormalities ( $4.3 \%$ vs $10.1 \%$ ), gastrointestinal disorders ( $13.5 \%$ vs $7.2 \%$ ) and neurologic disorders (22.6\% vs $11.7 \%$ ). Severity of ADE was classified as ADEs with spontaneous regression, regression after symptomatic treatment, hospitalisation with no life threat, 
TABLE 2 Distribution of medications (anatomical therapeutic classification level 1 and 2) according to outcome after ED visit

\begin{tabular}{|c|c|c|}
\hline & Discharge $(n=45635)$ & Hospitalisation $(n=43221)$ \\
\hline A. Alimentary tract and metabolism & $9293(50.3)$ & $9192(49.7)$ \\
\hline A02. Drugs for acid-related disorders & $2774(51.1)$ & $2653(48.9)$ \\
\hline A03. Drugs for functional gastrointestinal disorders & $956(59.5)$ & $650(40.5)$ \\
\hline A06. Laxatives & $1207(51.2)$ & $1149(48.8)$ \\
\hline A10. Drugs used in diabetes & $2181(47.9)$ & $2369(52.1)$ \\
\hline A12. Supplementation & $720(44.4)$ & $900(55.6)$ \\
\hline Others & $1455(49.7)$ & $1471(50.3)$ \\
\hline B. Blood and blood forming organs & $3953(47,1)$ & $4441(52.9)$ \\
\hline B01. Antithrombotic agents & $3360(47.5)$ & $3721(52.5)$ \\
\hline Others & $593(45.2)$ & $720(54.8)$ \\
\hline C. Cardiovascular system & $9832(48.3)$ & $10531(51.7)$ \\
\hline C01. Cardiac therapy & $1109(47.1)$ & $1244(52.9)$ \\
\hline C03. Diuretics & $1413(41.4)$ & $1999(58.6)$ \\
\hline c07. B-blocking agents & $1678(48.4)$ & $1791(51.6)$ \\
\hline C08. Calcium channel blockers & $1005(46.7)$ & $1145(53.3)$ \\
\hline C09. Agents acting on the renin-angiotensin system & $2440(51.5)$ & $2294(48.5)$ \\
\hline C10. Lipid-modifying agents & $1857(52.0)$ & $1714(48.0)$ \\
\hline Others & $330(49.0)$ & $344(51.0)$ \\
\hline D. Dermatologicals & $562(51.5)$ & $530(48.5)$ \\
\hline G. Genitourinary system and sex hormones & $1307(52.9)$ & $1164(47.1)$ \\
\hline G04. Urological drugs & $907(47.9)$ & $987(52.1)$ \\
\hline Others & $400(69.3)$ & $177(30.7)$ \\
\hline H. Systemic hormonal preparations & $1358(51.4)$ & $1286(48.6)$ \\
\hline H03. Thyroid therapy & $846(54.8)$ & $698(45.2)$ \\
\hline Others & $512(46.5)$ & $588(53.5)$ \\
\hline J. Anti-infective drugs for systematic use & $1125(49.5)$ & $1150(50.5)$ \\
\hline J01. Antibacterial drugs for systematic use & $954(49.8)$ & $961(50.2)$ \\
\hline Others & $171(47.5)$ & $189(52.5)$ \\
\hline L. Antineoplastic and immunomodulating agents & $399(43.9)$ & $509(56.1)$ \\
\hline M. Muscular-skeletal system & $1706(58.2)$ & $1224(41.8)$ \\
\hline M.01 Anti-inflammatory and antirheumatic products & $1065(65.3)$ & $566(34.7)$ \\
\hline Others & $641(49.3)$ & $658(50.7)$ \\
\hline N. Nervous system & $12573(55.2)$ & $10213(44.8)$ \\
\hline N02. Analgesics & $4622(55.5)$ & $3700(44.5)$ \\
\hline N03. Antiepileptic drugs & $1022(55.5)$ & $820(44.5)$ \\
\hline N05. Psycholeptics & $4020(55.5)$ & $3220(44.5)$ \\
\hline N06. Psychoanaleptics & $2112(53.0)$ & $1871(47.0)$ \\
\hline Others & $797(57.0)$ & $602(43.0)$ \\
\hline R. Respiratory system. & $2658(56.0)$ & $2089(44.0)$ \\
\hline R03. Antiasthmatics & $1584(52.9)$ & $1412(47.1)$ \\
\hline Other & $1074(61.3)$ & $677(38.7)$ \\
\hline S. Sensory organs & $526(48.1)$ & $568(51.9)$ \\
\hline Others & $343(51.4)$ & $324(48.6)$ \\
\hline
\end{tabular}


TABLE 3 Description of adverse drug event symptoms according to Emergency Department visit outcomes

\begin{tabular}{|c|c|c|}
\hline & $\begin{array}{l}\text { Discharge } \\
(n=1463)\end{array}$ & $\begin{array}{l}\text { Hospitalisation } \\
(n=1386)\end{array}$ \\
\hline Bleeding & $294(20.1)$ & $447(32.2)$ \\
\hline Gastrointestinal bleeding & 38 & 160 \\
\hline Haematoma & 89 & 81 \\
\hline $\begin{array}{l}\text { Haematuria/haemoptysis/ } \\
\text { epistaxis }\end{array}$ & 75 & 59 \\
\hline Intracranial haemorrhage & 27 & 72 \\
\hline Others & 65 & 75 \\
\hline Cardiovascular disorders & $132(9.0)$ & $107(7.7)$ \\
\hline Hypotension & 39 & 29 \\
\hline $\begin{array}{l}\text { Cardiac rhythm disorders/ } \\
\text { tachycardia/bradycardia }\end{array}$ & 30 & 30 \\
\hline Hypertension & 29 & 8 \\
\hline Others & 34 & 40 \\
\hline Fatigue/fall & $51(3.5)$ & $35(2.5)$ \\
\hline Gastrointestinal disorders & $197(13.5)$ & $100(7.2)$ \\
\hline Constipation & 54 & 34 \\
\hline Abdominal pain/diarrhoea & 56 & 21 \\
\hline Nausea/vomiting & 50 & 19 \\
\hline Gastroduodenal pain & 31 & 10 \\
\hline Others & 6 & 16 \\
\hline $\begin{array}{l}\text { Haematology and coagulation } \\
\text { test abnormalities }\end{array}$ & $63(4.3)$ & $140(10.1)$ \\
\hline Increase of blood INR values & 47 & 106 \\
\hline Others & 16 & 34 \\
\hline Infections & $29(2.0)$ & $62(4.5)$ \\
\hline Pneumonia & 4 & 19 \\
\hline Others & 25 & 43 \\
\hline Metabolic disorders & $183(12.5)$ & $233(16.8)$ \\
\hline Electrolyte disorders & 82 & 114 \\
\hline $\begin{array}{l}\text { Hyperglycaemia/ } \\
\text { hypoglycaemia }\end{array}$ & 81 & 72 \\
\hline Others & 20 & 47 \\
\hline Neurologic disorders & $331(22.6)$ & $162(11.7)$ \\
\hline $\begin{array}{l}\text { Altered consciousness/ } \\
\text { confusion/discomfort }\end{array}$ & 173 & 117 \\
\hline Convulsion & 100 & 20 \\
\hline Others & 58 & 25 \\
\hline Pulmonary disorders & $28(1.9)$ & $31(2.2)$ \\
\hline Psychological disorders & $24(1.6)$ & $13(0.9)$ \\
\hline Skin diseases & $83(5.7)$ & $27(1.9)$ \\
\hline Allergic reactions & 45 & 14 \\
\hline Urticaria & 26 & 1 \\
\hline Other & 12 & 12 \\
\hline Others & $48(3.3)$ & $29(2.1)$ \\
\hline
\end{tabular}

Note: Data are $\mathrm{n}(\%)$.

Abbreviation: INR, International Normalised Ratio. hospitalisation with life-threatening risk and death respectively at $6.7 \%, 47.4 \%, 38.8 \%, 5.7 \%$ and $1.2 \%$, respectively.

\section{4 | Variables associated with hospitalisation}

The results of the univariate and multivariate analysis for the variables associated with hospitalisation are described in Table 4. In the final model, 15 variables were independent predictors of hospital admission. Variables associated with increased hospital admission included 2 demographic variables (increasing age and male gender), 4 clinical variables (renal and hepatic failure, alcohol addiction, ED visit for respiratory reason) and 6 medication-related variables: polypharmacy (number of medications greater than 5), the use of blood, systemic anti-infective, metabolism and antineoplastic/immunomodulating medications, and the occurrence of an ADE. Conversely, an ED visit without immediate need of urgent care (FRENCH triage scale level 5), and an ED visit for cardiovascular and hepato-gastrointestinal reasons were negatively associated with hospital admission.

\section{4 | DISCUSSION}

A rapid identification and management of patients at risk of hospitalisation are crucial during the ED visit. In a subacute medical ED, physicians need to quickly refer patients and anticipate hospitalisation needs in order to relieve overcrowding. In total, $41.2 \%$ of our population was hospitalised following their admission to the subacute medical ED. We highlighted some of the variables associated with hospitalisation such as age, male gender, renal and hepatic failures, polypharmacy, blood, systemic anti-infective, metabolism, antineoplastic and immunomodulating medications, and ADE.

Our hospitalisation rate from a subacute medical ED visit is very close to those found in the literature. Three retrospective studies covering 1232 016, 1721294 and 100123 visits found hospitalisation rates of $38.7 \%, 40.7 \%$ and 38.6 , respectively. ${ }^{8-10}$ Moreover, the populations of these studies are very close to ours in terms of age (adult with mean age around 50 years old), sex ratio (near to 1) and triage category. However, our study population is not representative of the general population of an emergency department but rather corresponds to a sub-acute emergency population with a higher age and triage level and especially a higher rate of hospitalisation.

We identified standard admission data (age, male gender, triage level), clinical data (main cause of ED visit, comorbidity) and medication data (number of drugs, medication classes, ADE) as factors influencing the outcome after an ED visit in our population. Standard admission data are the most tested variables and are commonly integrated in ED admission prediction models, notably because they are readily and rapidly available. Thus, several retrospective studies involving thousands of patients share the same candidate predictor variables, particularly demographic data (age, gender or race), administrative data (day or time of arrival, mode of arrival, previous ED admission...) and other admission data (triage score). ${ }^{7-11,23}$ The 
TABLE 4 Univariate and multivariable analyses of variables associated with hospitalisation

\begin{tabular}{|c|c|c|c|c|}
\hline & \multicolumn{2}{|l|}{ Univariate analysis } & \multicolumn{2}{|c|}{ Multivariable analysis } \\
\hline & Odds ratio $95 \% \mathrm{Cl}$ & $P$-value & Odds ratio $95 \% \mathrm{Cl}$ & $P$-value \\
\hline Age (for 5 y) & $1.14(1.13-1.15)$ & $<.0001$ & $1.11(1.09-1.12)$ & $<.0001$ \\
\hline Male gender & $1.16(1.09-1.24)$ & $<.0001$ & $1.22(1.13-1.32)$ & $<.0001$ \\
\hline Body mass index $\geq 30 \mathrm{~kg} / \mathrm{m}^{2}$ ) (yes vs no) & $1.17(1.06-1.31)$ & .003 & & \\
\hline In institution (yes vs no) & $1.32(1.19-1.47)$ & $<.0001$ & & \\
\hline \multicolumn{5}{|l|}{ Comorbidities } \\
\hline Renal failure (GFR $<60 \mathrm{~mL} / \mathrm{min} / 1.73 \mathrm{~m}^{2}$ ) (yes vs no) & $2.06(1.84-2.31)$ & $<.0001$ & $1.30(1.14-1.48)$ & .0001 \\
\hline Hepatic failure (yes vs no) & $2.10(1.67-2.65)$ & $<.0001$ & $1.69(1.29-2.20)$ & .0001 \\
\hline Psychiatric disease (Yes Vs No) & $1.08(0.98-1.18)$ & .13 & & \\
\hline Dementia (yes vs no) & $1.56(1.39-1.74)$ & $<.0001$ & & \\
\hline Alcohol addiction (yes vs no) & $1.16(0.99-1.35)$ & .066 & $1.23(1.03-1.47)$ & .024 \\
\hline Tobacco use (yes vs no) & $0.60(0.55-0.65)$ & $<.0001$ & & \\
\hline \multicolumn{5}{|l|}{ Triage } \\
\hline FRENCH triage scale level 5 (yes vs other levels) & $0.54(0.48-0.61)$ & $<.0001$ & $0.62(0.54-0.71)$ & $<.0001$ \\
\hline \multicolumn{5}{|l|}{ Cause of ED visit } \\
\hline Cardiovascular (vs other causes of ED visit) & $0.62(0.56-0.69)$ & $<.0001$ & $0.66(0.59-0.75)$ & $<.0001$ \\
\hline Hepato-gastrointestinal (vs other causes of ED visit) & $0.64(0.59-0.70)$ & $<.0001$ & $0.51(0.38-0.70)$ & $<.0001$ \\
\hline Genitourinary (vs other causes of ED visit) & $0.54(0.42-0.70)$ & $<.0001$ & & \\
\hline Neurologic (vs other causes of ED visit) & $0.95(0.83-1.08)$ & .41 & & \\
\hline Respiratory (vs other causes of ED visit) & $2.13(1.93-2.35)$ & $<.0001$ & $1.49(1.32-1.68)$ & $<.0001$ \\
\hline Number of drugs $>5$ (vs $\leq 5)$ & $2.31(2.16-2.47)$ & $<.0001$ & $1.19(1.07-1.33)$ & .0014 \\
\hline \multicolumn{5}{|l|}{ Medications (ATC Level 1) } \\
\hline B. Blood and blood-forming organs (vs other medication types) & $2.13(1.99-2.27)$ & $<.0001$ & $1.12(1.02-1.24)$ & .017 \\
\hline $\begin{array}{l}\text { L. Antineoplastic and immunomodulating agents (vs other } \\
\text { medication types) }\end{array}$ & $1.84(1.58-2.14)$ & $<.0001$ & $1.64(1.37-1.96)$ & $<.0001$ \\
\hline J. Anti-infective drugs for systemic use (vs other medication types) & $1.44(1.30-1.58)$ & $<.0001$ & $1.31(1.17-1.48)$ & $<.0001$ \\
\hline N. Nervous system (vs other medication types) & $1.34(1.25-1.44)$ & .0002 & & \\
\hline C. Cardiovascular system (vs other medication types) & $2.33(2.18-2.50)$ & $<.0001$ & & \\
\hline A. Alimentary tract and metabolism (vs other medication types) & $1.92(1.79-2.05)$ & $<.0001$ & $1.17(1.06-1.29)$ & .0024 \\
\hline R. Respiratory system (vs other medication types) & $1.08(1.00-1.18)$ & .067 & & \\
\hline ADE (yes vs no) & $1.46(1.34-1.59)$ & $<.0001$ & $1.28(1.15-1.42)$ & $<.0001$ \\
\hline
\end{tabular}

Abbreviations: ADE, adverse drug event; ATC, anatomical therapeutic classification; $\mathrm{Cl}$, confidence intervals; ED, emergency department; FRench Emergency Nurses Classification in Hospital scale (FRENCH), level 5: no functional impairment or organic lesion justifying the use of hospital resources; GFR, glomerular filtration rate.

variables most significantly associated with hospitalisation in these studies are increasing age and urgent triage level, as found in our study, as well as arrival by ambulance.

Some authors have also investigated the link between hospitalisation after the ED visit and clinical variables such as blood test request, ${ }^{9}$ presence of a chronic condition ${ }^{23}$ or main cause of the ED visit. ${ }^{8,9,11}$ Like Dinh et al, we found a relation between reasons of ED visit and risk of hospitalisation. ${ }^{8}$ It is difficult to compare our results due to possible differences in categorisation of presenting symptoms. Indeed, we used the clinical categorisation system whose principal limitation overlaps between categories. Moreover, due to our smaller dataset, we evaluated 5 major causes of admission, while Dinh et al evaluated 18 . However, like them, we observe that cardiovascular causes of ED visits decrease the probability of hospitalisation. Concerning chronic diseases, none of the conditions investigated and reported by Sun et $\mathrm{al}^{23}$-as associated with the admission risk (diabetes, hypertension or dyslipidemia)-have been tested in our study. However, we identified chronic kidney and hepatic failures as a factor associated with hospitalisation.

In our study, we finally assessed the impact of medication and the presence of an ADE on the risk of hospitalisation. This was made possible by our organisation and by the presence of a pharmaceutical team in the ED, allowing us to add these therapeutic data as routinely collected candidate predictor variables. Thus, we were able to show that a significant number of drugs (more than 5), treatment by antineoplastic and immunomodulating agents, blood, systemic 
anti-infective, metabolism medications, and the presence of an ADE were significantly associated with hospitalisation in multivariate analyses. Polypharmacy and prescribed medication have already been tested and included in several models designed for primary care. ${ }^{5}$ However, to our knowledge, no hospitalisation prediction model designed for ED patients has ever investigated medication and ADErelated variables. We found only 1 retrospective study evaluating patient treatment through electronic health record, ${ }^{24}$ but primary care databases are often incomplete or out of date. ${ }^{25}$ Unavailability or poor accuracy of the patients' medication history in the ED ${ }^{26,27}$ may partly explain the low utilisation of medication and ADE-related data in ED admission prediction models, as well as the difficulty of detecting ADEs and the problem of their under-reporting. ${ }^{28-32}$

Moreover, unlike some ambulatory models, we did not focus on the presence or absence of specific medication ${ }^{33}$ but recorded prospectively all the drugs taken by the patient. This allowed us to highlight the implication of drugs that were less investigated, or less prescribed. We were thus able to identify antineoplastic and immunomodulating agents, blood, systemic anti-infective and metabolism medications as medications associated with hospitalisation risk in the subacute medical ED. These medications have already been linked to hospital admission due to drug-related problems. ${ }^{15,34}$ As polypharmacy is also a well-known risk factor of $A D E,{ }^{35}$ it is therefore not surprising that our third medication-related factor for admission was the occurrence of an ADE. A greater proportion of hospitalisation in ED patients with an ADE has already been found in several studies and only in univariate analyses. ${ }^{16,36-38}$

To our knowledge, this is the first prospective study to have highlighted ADEs as a factor independently associated with hospitalisation following admission to a subacute medical ED. Furthermore, the integration of the clinical pharmacist team in the ED for medication history collection ensured a high level of ADE detection and a rigorous prospective data collection, in particular concerning medication. This large data collection and our large sample size are major strengths of our study.

\section{1 | Study limitations}

Our study also has some limitations, mainly due to its monocentric design and recruitment method. Indeed, we did not analyse some of the variables described in the literature such as previous ED visits or hospitalisation, mode of arrival at the ED, vital signs or more comorbidities which might have been of interest. The detection of ADEs was performed by the clinical pharmacist and the emergency physician and only contentious cases were reviewed by the expert committee. An evaluation of all cases would have been more robust. In our study, ADEs were detected jointly by the clinical pharmacist and the emergency physician, then reviewed by an expert committee when deemed necessary. Similar methodology has been used in several comparable studies. ${ }^{31,37,39,40}$ However, some studies have used external or independent expert committees for ADE verification. $^{36,41}$ Finally, possible selection bias due to the recruitment procedure questions the generalisation of our results. For this study, we did not include patients from the outpatient unit as their duration of care was not compatible with the study process and their probability of hospitalisation was extremely low or even null. Exclusion of specialised units and outpatient unit can account for our population being older, with more medication and more prone to hospitalisation. This may have introduced a selection bias. However, our objective was to highlight the risk factors associated with hospitalisation and improve patient flow and admission process. We therefore carried out this study in units in line with this objective, where patients' flow was difficult to manage, with long waiting times.

\section{5 | CONCLUSION}

In summary, in a large ED population ( $n=14511$ ), we identified independent predictors for hospitalisation following the ED visit. Besides commonly tested variables, we investigated the potential implication of medication on patient disposition. Thus, in addition to standard admission and clinical data, we have identified variables associated with treatments (polypharmacy, treatment by antineoplastic or immunomodulating agents, blood, systemic anti-infective and metabolism medications and presence of an ADE). These results point out the importance and relevance of collecting medication data in the context of a subacute medical ED visit.

\section{ACKNOWLEDGEMENTS}

The authors acknowledge the pharmacy residents and students of the clinical pharmacy department, the emergency physicians and nurses and the Emergency Department at Montpellier University Hospital for their ongoing support throughout the study.

\section{REFERENCES}

1. Steventon A, Deeny S, Friebal R, Gadner T, Thorlby R. Emergency hospital admissions in England: which may be avoidable and how?. The Health Fondation; 2018. https://www.health.org.uk/publications/ emergency-hospital-admissions-in-england-which-may-be-avoid able-and-how. Accessed April 27, 2020.

2. National Audit Office. Reducing Emergency Admissions; 2018. https://www.nao.org.uk/report/reducing-emergency-admissions. Accessed April 27, 2020.

3. Krumholz HM. Post-hospital syndrome-an acquired, transient condition of generalized risk. N Engl J Med. 2013;368:100-102.

4. Purdy S. Avoiding hospital admission; what does the research evidence say?. The King's Fund; 2010. https://www.kingsfund.org.uk/sites/ default/files/Avoiding-Hospital-Admissions-Sarah-Purdy-Decem ber2010.pdf. Accessed July 15, 2020.

5. Wallace E, Stuart E, Vaughan N, BennettK, Fahey T, Smith SM. Risk prediction models to predict emergency hospital admission in communitydwelling adults: a systematic review. Med Care. 2014;52:751-765.

6. Kingston MR, Evans BA, Nelson K, Hutchings H, Russell I, Snooks $H$. Costs, effects and implementation of routine data emergency 
admission risk prediction models in primary care for patients with, or at risk of, chronic conditions: a systematic review protocol. BMJ Open. 2016;6:e009653.

7. Cameron A, Rodgers K, Ireland A, Jamdar R, McKay GA. A simple tool to predict admission at the time of triage. Emerg Med J. 2015;32:174-179.

8. Dinh MM, Russell SB, Bein KJ, et al. The Sydney Triage to Admission Risk Tool (START) to predict Emergency Department Disposition: a derivation and internal validation study using retrospective state-wide data from New South Wales, Australia. BMC Emerg Med. 2016;16:46.

9. Kim SW, Li JY, Hakendorf P, Teubner DJ, Ben-Tovim DI, Thompson $\mathrm{CH}$. Predicting admission of patients by their presentation to the emergency department. Emergency Med Aust. 2014;26:361-367.

10. Parker CA, Liu N, Wu SX, Shen Y, Lam SSW, Ong MEH. Predicting hospital admission at the emergency department triage: a novel prediction model. Am J Emerg Med. 2019;37:1498-1504.

11. Peck JS, Benneyan JC, Nightingale DJ, Gaehde SA. Predicting emergency department inpatient admissions to improve same-day patient flow. Acad Emergency Med. 2012;19:E1045-E1054.

12. Sun BC, Hsia RY, Weiss RE, et al. Effect of emergency department crowding on outcomes of admitted patients. Ann Emergency Med. 2013;61:605-611.e6.

13. Sun BC, Adams J, Orav EJ, Rucker DW, Brennan TA, Burstin HR. Determinants of patient satisfaction and willingness to return with emergency care. Ann Emergency Med. 2000;35:426-434.

14. Derlet RW, Richards JR. Overcrowding in the nation's emergency departments: complex causes and disturbing effects. Ann Emergency Med. 2000;35:63-68.

15. Ayalew MB, Tegegn HG, Abdela OA. Drug Related Hospital Admissions; A systematic review of the recent literatures. Bull Emergency Trauma. 2019;7:339-346.

16. Laureau M, Vuillot O, Gourhant V, et al. Adverse drug events detected by clinical pharmacists in an emergency department: a prospective monocentric observational study. J Patient Saf. 2020. https://doi.org/10.1097/PTS.0000000000000679

17. van den Bemt PM, van der Schrieck-de Loos EM, van der Linden C, Theeuwes AM, Pol AG; Dutch CBOWHOHsSG. Effect of medication reconciliation on unintentional medication discrepancies in acute hospital admissions of elderly adults: a multicenter study. $J$ Am Geriatr Soc. 2013;61:1262-1268.

18. Breuker C, Macioce V, Mura T, et al. Medication errors at hospital admission and discharge: risk factors and impact of medication reconciliation process to improve healthcare. J Patient Saf. 2017. https://doi.org/10.1097/PTS.0000000000000420

19. Institute of Medicine Committee on Quality of Health Care. Errors in health care: a leading cause of death and injury. In: Kohn LT, Corrigan JM, Donaldson MS, eds. To Err is Human: Building a Safer Health System. Washington (DC): National Academies Press (US); 2000.

20. Arimone Y, Bidault I, Dutertre JP, et al. Updating the French method for the causality assessment of adverse drug reactions. Therapie. 2013;68:69-76.

21. Naranjo CA, Busto U, Sellers EM, et al. A method for estimating the probability of adverse drug reactions. Clin Pharmacol Ther. 1981;30:239-245.

22. Taboulet P, Moreira V, Haas L, et al. Triage with the French Emergency Nurses Classification in Hospital scale: reliability and validity. Eur J Emerg Med. 2009;16:61-67.

23. Sun Y, Heng BH, Tay SY, Seow E. Predicting hospital admissions at emergency department triage using routine administrative data. Acad Emergency Med. 2011;18:844-850.

24. Hong WS, Haimovich AD, Taylor RA. Predicting hospital admission at emergency department triage using machine learning. PLoS One. 2018;13:e0201016.

25. Lyon D, Lancaster GA, Taylor S, Dowrick C, Chellaswamy H. Predicting the likelihood of emergency admission to hospital of older people: development and validation of the Emergency Admission Risk Likelihood Index (EARLI). Fam Pract. 2007;24:158-167.

26. Caglar S, Henneman PL, Blank FS, Smithline HA, Henneman EA. Emergency department medication lists are not accurate. J Emergency Med. 2011;40:613-616.

27. Mazer M, Deroos F, Hollander JE, McCusker C, Peacock N, Perrone J. Medication history taking in emergency department triage is inaccurate and incomplete. Acad Emergency Med. 2011;18:102-104.

28. Stergiopoulos S, Brown CA, Felix T, Grampp G, Getz KA. A survey of adverse event reporting practices among US healthcare professionals. Drug Saf. 2016;39:1117-1127.

29. Hazell L, Shakir SA. Under-reporting of adverse drug reactions: a systematic review. Drug Saf. 2006;29:385-396.

30. Howe CL. A review of the Office of Inspector General's reports on adverse event identification and reporting. $J$ Healthc Risk Manage. 2011;30:48-54.

31. Roulet L, Ballereau F, Hardouin JB, et al. Assessment of adverse drug event recognition by emergency physicians in a French teaching hospital. Emergency Med J. 2013;30:63-67.

32. Tam VC, Knowles SR, Cornish PL, Fine N, Marchesano R, Etchells EE. Frequency, type and clinical importance of medication history errors at admission to hospital: a systematic review. CMAJ. 2005;173:510-515.

33. Hippisley-Cox J, Coupland C. Predicting risk of emergency admission to hospital using primary care data: derivation and validation of QAdmissions score. BMJ Open. 2013;3:e003482.

34. Nivya K, Sri Sai Kiran V, Ragoo N, Jayaprakash B, Sonal SM. Systemic review on drug related hospital admissions - a pubmed based search. Saudi Pharm J. 2015;23:1-8.

35. Jatau AI, Shitu Z, Khalid GM, Yunusa I, Awaisu A. Understanding adverse drug-related emergency department visits: development of a conceptual model through a systematic review. Ther Adv Drug Saf. 2019;10:1-18.

36. Zed PJ, Abu-Laban RB, Balen RM, et al. Incidence, severity and preventability of medication-related visits to the emergency department: a prospective study. CMAJ. 2008;178:1563-1569.

37. Hafner JW Jr, Belknap SM, Squillante MD, Bucheit KA. Adverse drug events in emergency department patients. Ann Emergency Med. 2002;39:258-267.

38. Trifiro G, Calogero G, Ippolito FM, et al. Adverse drug events in emergency department population: a prospective Italian study. Pharmacoepidemiol Drug Saf. 2005;14:333-340.

39. Asseray N, Ballereau F, Trombert-Paviot B, et al. Frequency and severity of adverse drug reactions due to self-medication: a crosssectional multicentre survey in emergency departments. Drug Saf. 2013;36:1159-1168.

40. Nickel CH, Ruedinger JM, Messmer AS, et al. Drug-related emergency department visits by elderly patients presenting with non-specific complaints. Scand J Trauma Resusc Emergency Med. 2013;21:15.

41. Hohl CM, Nosyk B, Kuramoto L, et al. Outcomes of emergency department patients presenting with adverse drug events. Ann Emergency Med. 2011;58:270-279.e4. 